\title{
Mikroskop İncelemesi Negatif Olan Şüpheli Kronik Kutanöz Leishmania Olgularının Polimeraz Zincir Reaksiyonu Yöntemi ile Araştırılması
}

\author{
Investigation of Polymerase Chain Reaction Method in Patients \\ with Suspected Chronic Cutaneous Leishmania of \\ Negative Microscopy
}

\author{
Gülnaz ÇULHA ${ }^{1}$, Tuğba KAYA ${ }^{1}$, Gülay GÜLBOL DURAN² ${ }^{2}$, Meral URHAN KÜÇÜK², \\ Asena Çiğdem DOČRAMACl ${ }^{3}$, Dilek TiYEKLi ÇELiK ${ }^{4}$ \\ ${ }^{1}$ Hatay Mustafa Kemal Üniversitesi Tıp Fakültesi, Parazitoloji Anabilim Dalı, Hatay. \\ ${ }^{1}$ Hatay Mustafa Kemal University Faculty of Medicine, Department of Parasitology, Hatay, Turkey. \\ ${ }^{2}$ Hatay Mustafa Kemal Üniversitesi Tıp Fakültesi, Tıbbi Biyoloji Anabilim Dalı, Hatay. \\ ${ }^{2}$ Hatay Mustafa Kemal University Faculty of Medicine, Department of Medical Biology, Hatay, Turkey. \\ ${ }^{3}$ Hatay Mustafa Kemal Üniversitesi Tıp Fakültesi, Deri ve Zührevi Hastalıkları Anabilim Dalı, Hatay. \\ ${ }^{3}$ Hatay Mustafa Kemal University Faculty of Medicine, Department of Dermatology, Hatay, Turkey. \\ ${ }^{4}$ Trakya Üniversitesi Sağlık Bilimleri Enstitüsü, İmmünoloji Anabilim Dalı, Edirne. \\ ${ }^{4}$ Trakya University Institute of Health Sciences, Department of Immunology, Edirne, Turkey.
}

* Bu çalışma, Hatay Mustafa Kemal Üniversitesi Bilimsel Araştırma Projeleri Koordinatörlüğü Birimi tarafından (Proje numarası: 18.M.004) desteklenmiștir.

Makale Atıfı: Çulha G, Kaya T, Gülbol Duran G, Urhan Küçük M, Doğramacı AÇ, Tiyekli Çelik D. Mikroskop incelemesi negatif olan şüpheli kronik kutanöz Leishmania olgularının polimeraz zincir reaksiyonu yöntemi ile araștırılması. Mikrobiyol Bul 2019;53(4):408-418.

\section{ÖZ}

Leyşmanyazis, enfekte dişi tatarcıkların ısırmasıyla insanlara bulaşan paraziter bir hastalıktır. Kutanöz leyşmanyazisin (KL) tanısında dermal kazıntıdan alınan örneklerde, mikroskopta parazitin gösterilmesi altın standart bir yöntem olarak yerini korumaktadır. Ancak bir yıl ve daha uzun süreli lezyonu bulunan kronik olgularda amastigot sayısı çok az sayıda olduğundan saptamak zordur. Hastaların öncelikle vücutlarında çıkan bu lezyonları dikkate almamaları, sağlık kurumlarına başvurmamaları veya geç başvurmaları, yanlış tedavi almaları gibi birçok nedenden ötürü tanı ve tedavi gecikmektedir. Ayrıca, lezyonlar üzerine sekonder enfeksiyon eklenerek prognoz kötüleşmekte ve yaralar kronikleşmektedir. Bu nedenle, kronik $\mathrm{KL}$ şüpheli olgularda mikroskop ile inceleme yöntemine ek olarak moleküler yöntemlerden faydalanılmaktadır. Bu çalışmada, mikroskop incelemesi sonucunda Leishmania amastigotları görülmeyen ancak klinik olarak KL açısından değerlendirilmesi rapor edilmiş şüpheli kronik KL Türkiye başlangıçlı olgulara ait dermal kazıntı preparatları seçilerek polimeraz zincir reaksiyonu (PCR) yöntemi kullanılarak leyşmanyazis tanısında moleküler yöntemin tanı değerinin ortaya konması amaçlanmıştır. Hatay Mustafa Kemal Üniversitesi Tıp Fakültesi Parazitoloji Laboratuvarına farklı polikliniklerden gelen KL şüphesi ile başvurmuş ve mikroskop incelemesi sonucunda endemik bölgelerden geldikleri kaydedilmiş (Hassa, Altınözü, Yayladağı 
gibi), klinik olarak kronik KL açısından değerlendirilmesi rapor edilmiş Türk hastaya ait dermal kazıntı preparatları $(n=50)$ çalışmaya dahil edilmiştir. Örneklerden DNA izolasyonu yapılarak tüm Leishmania türlerine özgü kinetoplastit DNA (kDNA) bölgesini hedefleyen 13A, 13B primerleri kullanılmıştır. PCR ile pozitif bulunan örnekler internal transcribed spacer (ITS-1) bölgesini hedefleyen LITSR ve L5.8S primerleri kullanılarak "polymerase chain reaction-restriction fragment length polymorphism (PCR-RFLP)" yöntemi ile tür tayini yapılmışır. Toplam 50 adet dermal kazıntı örneğinden 17 (\%34)'si kDNA bölgesini hedefleyen 13A, 13B primerleri ile pozitif olarak bulunmuştur. Pozitif bulunan örnekler ITS-1 bölgesini hedefleyen LITSR ve L5.8S primerleri ile de pozitif olarak saptanmıştır. ITS-1 gen bölgesiyle yapılan PCR sonucunda elde edilen ürünler BsuRI (HaellI) enzimi kullanılarak kesilmiştir. PCR-RFLP analizi sonucunda 17 örneğin 11'i Leishmania tropica, biri Leishmania major ve beşi Leishmania infantum/donovani olarak tanımlanmışır. Kronik KL; sarkoidoz, tüberküloz, malign tümörler gibi deri hastalıklarıyla karışabilmektedir. Özellikle, kronik KL olguları doğru tanı konulamaması, mikroskop deneyiminin yeterli olmaması, parazit sayısının az olması nedeniyle görülememesi gibi pek çok sebepten gözden kaçabilmektedir. Bu nedenle kronik KL şüphesi olan ancak mikroskop inceleme yöntemi ile parazit saptanamayan örneklerde moleküler yöntem olan PCR'nin kullanıımasının gerektiği sonucuna varılmıştır.

Anahtar kelimeler: Kronik şüpheli leyșmanyazis; tanı; polimeraz zincir reaksiyonu; restriction fragment length polymorphism.

\section{ABSTRACT}

Leishmaniasis is a parasitic disease that is transmitted to humans by the bites of infected female phlebotomine sandflies. In the diagnosis of cutaneous leishmaniasis $(\mathrm{CL})$, in the smear samples, the demonstration of the parasite by microscope remains a gold standard method. However, it becomes difficult to diagnose the parasite since the number of amastigotes in chronic cases with a lesion of one year or longer is very low. Due to many factor such as patients primarily do not to take any notice these lesions in their bodies, do not apply to health institutions or late applied, receive wrong treatment; the diagnosis and treatment are delayed. In addition, it is been worse prognosis by add secondary infection to lesions and wounds become chronic. For this reason, molecular methods are used in addition to microscopic examination in chronic suspected $\mathrm{CL}$ cases. It was aimed to reveal of the molecular diagnostic value in chronic suspected $\mathrm{CL}$ cases by polymerase chain reaction (PCR) in the smear belonging to Turkish patients that reported to be evaluated clinically because it can not be seen Leishmania amastigotes in microscopic examination. Smear of 50 Turkish patients who were clinically reported of the evaluation of chronic $\mathrm{CL}$ were selected. These samples were smears belonging to suspected $\mathrm{CL}$ patients that applied Hatay Mustafa Kemal University, Faculty of Medicine, Parasitology laboratory from different polyclinics and were decided to be evaluated clinically as a result of microscopic examination because they came from endemic regions (such as Hassa, Altınözü, Yayladağı). DNA was isolated from selected samples and PCR was performed using 13A, 13B primers targeting the kinetoplastid DNA (KDNA) region. The samples found positive by PCR were typed by polymerase chain reaction-restriction fragment length polymorphism (PCR-RFLP) analysis using LITSR and L5.8S primers targeting internal transcribed spacer (ITS-1) region. Of the 50 smear samples, 17 (34\%) were determined positive with 13A, 13B primers targeting the kinetoplastid DNA (kDNA) region. Positive samples were also found to be positive with LITSR and L5.8S primers targeting ITS-1 region. The PCR products obtained from PCR with ITS-1 gene region were digested with the restriction endonucleases BsuRI (HaellI). As a result of PCR-RFLP analysis, it was determined that 11 of Leishmania tropica, one of Leishmania major and five of Leishmania infantum/donovani out of 17 samples. Chronic CL can be confused with skin diseases such as sarcoidosis, tuberculosis, malignant tumors. In particular, chronic $\mathrm{CL}$ cases can be escaped the attention for many reasons such as failure to diagnose correctly, insufficient microscope experience, fail to see due to low number of parasites. For this reason, it was concluded that PCR, which is a molecular method, should be used in chronic suspected CL samples which are negative for the parasite by microscopic examination.

Keywords: Chronic suspected leishmaniasis; diagnosis; polymerase chain reaction; restriction fragment length polymorphism. 


\section{Gíriş}

Leishmania cinsinde yer alan protozoonların neden olduğu kutanöz leyşmanyazis diğer adıyla şark çıbanı (KL), deride ve bazen mukozalarda yerleşen, iz bırakarak iyileşen bir deri hastalığıdır. Dünya Sağlık Örgütü (DSÖ) verilerine göre; leyşmanyazisin toplam 102 ülkede görüldüğü, her yıl yaklaşık 1.3 milyon yeni olgunun ortaya çıktığı, 300.000 olgunun viseral leyşmanyazis, bir milyon olgunun kutanöz ve mukokutanöz leyşmanyazis olduğu tahmin edilmektedir. KL olgularının çoğunlukla Suriye, İran, Suudi Arabistan, Afganistan, Cezayir, Brezilya, Pakistan, Kolombiya, Peru ve Tunus'da görüldüğü bilinmektedir ${ }^{1-3}$.

Ülkemizde Şanlıurfa, Osmaniye, Adana, Hatay gibi Güneydoğu ve Doğu Akdeniz bölgesindeki illerde KL sık olarak görülmektedir. Ancak son yıllarda diğer bölgelerde bulunan illerde de sporadik olgular şeklinde görülmeye başlanmıştır ${ }^{4-6}$. KL'nin endemik olarak görüldüğü sınır komşularımız arasında yer alan Suriye'den 2011 yılından sonra ülkelerinde yaşanan savaştan kaçarak ülkemize sığınan yaklaşık 3 milyondan fazla mültecinin ülkemize gelmesiyle de KL olgularının oranında önemli bir artış gözlenmiştir ${ }^{7}$. Bu durum, hastalığın endemik olarak görüldüğü illerde olgu sayısının artışına neden olabileceği ihtimalini düşündürmektedir.

Türkiye'nin Doğu Akdeniz Bölgesi'nde yer alan Hatay'da 1998-2005 yılları arasında 1079 adet KL olgusu görülmüştür ${ }^{8}$. Bu tarihten 2011 yılına kadar olan süreçte ise olgu sayılarında bir azalma meydana gelmiştir ${ }^{9}$. Ancak 2011 yılından sonra Suriye'den ülkemize sığınan mülteciler ile birlikte ülke genelinde olduğu gibi Hatay ilinde de KL olguları daha çok görülmeye başlanmışıı ${ }^{7,9}$. Bölgede Phlebotomus sergenti, Phlebotomus papatasi ve Phlebotomus syriacus'un KL'ye neden olan olası vektörler olabileceği bildirilmiştir ${ }^{10}$. Bölgede KL'ye neden olan Leishmania türlerinin Leishmania infantum/donovani, Leishmania major ve Leishmania tropica olduğu geçmiş yıllarda yapılan çalışmalarda saptanmıştır ${ }^{11-13}$.

$\mathrm{KL}$ şüpheli, özellikle bir yıldan uzun süredir lezyonu bulunan kronik olgularda ve lezyonlarında sekonder enfeksiyon gelişmiş olanlarda mikroskop incelemesi yetersiz olabilmektedir ${ }^{8}$. Kronik olgularda amastigot sayısı çok az olduğundan mikroskobik incelemede saptamak zordur. Hastaların öncelikle vücutlarında oluşan bu lezyonları dikkate almamaları, sağlık kurumlarına geç başvurmaları veya başvurmamaları, yanlış tedavi almaları gibi birçok nedenden dolayı tanı ve tedavi gecikmekte ve lezyonlara sekonder enfeksiyonlar eklenerek kronikleşmektedir ${ }^{6}$. Ayrıca KL; egzema, tüberküloz, sifilis, mantar enfeksiyonları ve bazen de skuamöz hücreli karsinom gibi diğer deri hastalıklarına klinik olarak benzerlik göstermektedir. Bu durum KL tanısını zorlaştırmaktadır ${ }^{14}$.

KL'nin laboratuvar tanısında; doğrudan (yayma preparat, kültür gibi) veya dolaylı pek çok yöntem kullanılmakla birlikte en sık kullanılanı, lezyonlardan hazırlanan yayma preparatlarda parazitin gösterilmesidir ${ }^{7}$. Yayma örneklerinin, mikroskop inceleme yöntemi ile değerlendirilmesi kolay ve güvenilir bir yöntemdir. Ancak uygun olmayan örnek alımı ve boyama tekniği, zayıf çözünürlüklü mikroskopların kullanımı ve deneyimli personelin 
olmaması gibi birçok faktör bu yöntemin duyarlılığını etkilemektedir. Bu sebeplerden dolayı duyarlıığı daha yüksek olan PCR yönteminden yararlanılmaktadır ${ }^{15}$.

Bu çalışmada, göç öncesi 2002-2010 yılları arasında kronik lezyonu bulunan ve KL şüphesiyle başvuran ancak mikroskop incelemesi sonucunda klinik olarak KL açısından değerlendirilmesi notu ile birlikte negatif olarak rapor edilmiş Türk hastalara ait preparatlar moleküler bir yöntem olan PCR ile araştırılmıştır. Bu çalışmada, endemik bölgede yaşayan ve kronik lezyonu bulunan hastalarda mikroskobik inceleme yöntemi ile yanlış negatif sonuç verilebileceğinin ve bu olgularda tanı konulurken moleküler tanı yöntemlerinin de kullanılması gerektiğinin ortaya konulması amaçlanmıştır.

\section{GEREÇ ve YÖNTEM}

Bu çalışma, Hatay Mustafa Kemal Üniversitesi Üniversitesi Tayfur Ata Sökmen Tıp Fakültesi Klinik Araştırmalar Etik Kurulu onayı ile gerçekleştirildi (Tarih: 01/03/2017 ve Karar no: 64).

\section{Örneklerin Toplanması}

2002-2010 yılları arasında Hatay Mustafa Kemal Üniversitesi (HMKÜ) Tıp Fakültesi Parazitoloji Laboratuvarına farklı polikliniklerden gelen, HMKÜ Tıp Fakültesi Merkez Laboratuvarı Parazitoloji biriminde KL açısından klinik olarak değerlendirilmesi gerektiği not düşülerek negatif olarak kayda geçmiş ancak ileri tanı teknikleri olmadığından şüpheli olgular olarak değerlendirilmiş olan Türk hastalara ait arşivde yer alan 50 adet kronik şüpheli KL preparatı seçildi.

\section{DNA İzolasyonu}

Arşivde saklanan Giemsa boyalı yayma örnekleri etanol ile yıkandı ve üzerine $200 \mu \mathrm{l}$ lizis tamponu (ml'sinde; $50 \mathrm{mM} \mathrm{NaCl}, 50 \mathrm{mM}$ Tris, $10 \mathrm{mM}$ EDTA, pH 7.4, \%1 v/v Triton $\mathrm{x}-100$ ve $100 \mu \mathrm{g}$ proteinaz k) eklendi. Bu işlemin ardından kazınarak steril tüplere alındı ${ }^{16}$ ve DNA izolasyon kiti (GeneJET Genomic DNA Purification Kit, Thermo Fisher, ABD) içinde bulunan protokole uygun olarak çalışıldı. Yöntemin uygulanması işlemine kadar elde edilen DNA'lar $-20^{\circ} \mathrm{C}^{\prime}$ de saklandı. Pozitif kontrol olarak Manisa Celal Bayar Üniversitesi Tıp Fakültesi Parazitoloji Laboratuvarı Parazit Bankasında bulunan referans örnekler kullanıldı.

\section{Gen Amplifikasyonu}

Leishmania kinetoplast DNA'sının (kDNA) 116 baz çifti (bp) bölümü 13A: 5'-dGT GGG GGA GGG GCG TTC T-3' ve 13B: 5'-dAT TTT ACA CCA ACC CCC AGT T-3' primerleri kullanılarak PCR ile çoğaltıldı. Çoğaltılan kDNA bölgesi ile pozitif olduğu saptanan örneklerde, genomik DNA'da, tür tayininde belirleyici BsuRI (HaellI) enzimi kesim bölgesi içeren ITS-1 bölgesi amplifiye edildi. ITS-1 bölgesi için LITSR: 5'-CTG GAT CAT TTT CCG ATG-3' ve L5.8S: 5'-TGA TAC CAC CAC TTA TCG CAC TT-3' primerleri kullanıldı.

PCR karışımı için $4 \mu \mathrm{l}$ 10x Taq polimeraz tamponu, $3 \mathrm{mM} \mathrm{MgCl}, 250 \mu \mathrm{M}$ dNTP karışımı, $0.5 \mathrm{U}$ Taq DNA polimeraz, $5 \mu \mathrm{l}$ kalıp DNA, her bir primerden 0.5 pikomol eklenerek 
toplam $50 \mu \mathrm{l}$ hacim olacak şekilde distile su eklendi. PCR analizlerinde $94^{\circ} \mathrm{C}^{\prime}$ de 7 dakika ön denatürasyonu takiben 35 döngü olmak üzere, $94^{\circ} \mathrm{C}^{\prime}$ de 40 saniye, $56^{\circ} \mathrm{C}^{\prime}$ de 40 saniye, $72^{\circ} \mathrm{C}^{\prime}$ de 40 saniye ve $72^{\circ} \mathrm{C}^{\prime}$ de 7 dakika son uzama olarak amplifikasyon işlemi Thermo Fisher SimpleAmp Thermal Cycler, ABD cihazında gerçekleştirildi. Elde edilen PCR ürünü \%1.5 agaroz jelde yürütüldü. Daha sonra BiO-RAD ChemiDoc Imaging System, ABD cihazı kullanılarak 116 bp büyüklüğünde PCR ürünlerine ait bantlar görüntülendi.

\section{PCR-RFLP}

LITSR ve L5.8S primerleri ile çoğaltılmış olan PCR ürünleri BsuRI (HaellI) restriksiyon enzimi ile kesildi. $5 \mu \mathrm{l}$ PCR ürünü, $2 \mu \mathrm{l}$ BsuRI enzimi, $2 \mu \mathrm{l}$ restriksiyon tamponu son hacmi $20 \mu$ olacak şekilde distile su ile tamamlandı. Bir gece $37^{\circ} \mathrm{C}^{\prime}$ de inkübe edildikten sonra ürünler \%3 agaroz jelde iki saat yürütüldü. Sonuçlar pozitif kontrol suşları (L.tropica, L.major, L.infantum/donovani) ile karşılaştırılarak değerlendirildi.

\section{BULGULAR}

Çalışmaya dahil edilen 50 negatif şüpheli yayma örneğinde tüm Leishmania türlerini tanıyabilen kDNA bölgesi özgül primer dizileri kullanılarak PCR ile çoğaltılmıştır. Toplam 17 (\%34) örnekte 116 bp uzunluğunda amplikonlar elde edilmiş ve pozitif olarak değerlendirilmiştir (Şekil 1). Pozitif olduğu saptanan 17 (\%34) örneğin ITS-1 bölgesini hedefleyen primerler kullanılarak tekrar PCR ile çoğaltılmış ve 350-350 bp uzunluğunda amplikonlar elde edilmiştir.

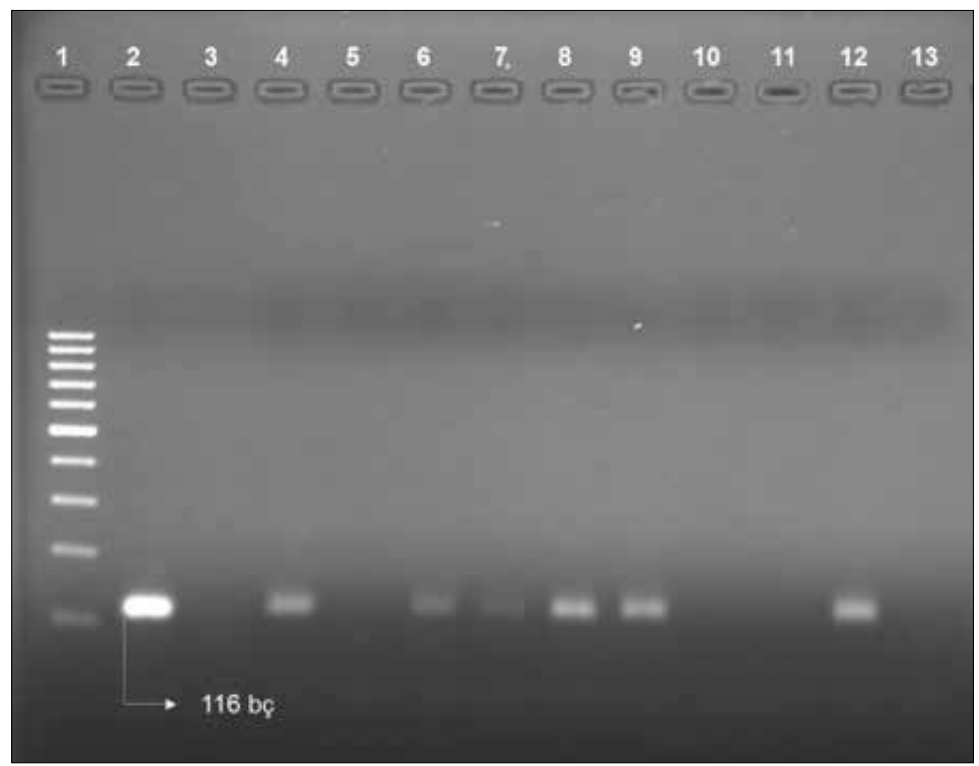

Şekil 1. Kutanöz leyşmanyazis şüpheli örneklerden kDNA kullanılarak gerçekleştirilmiş PCR [1: Moleküler ağırlık belirteci (100 bp) 2: PK (pozitif kontrol), 3: NK (negatif kontrol), 4-13: Hasta örnekleri]. 


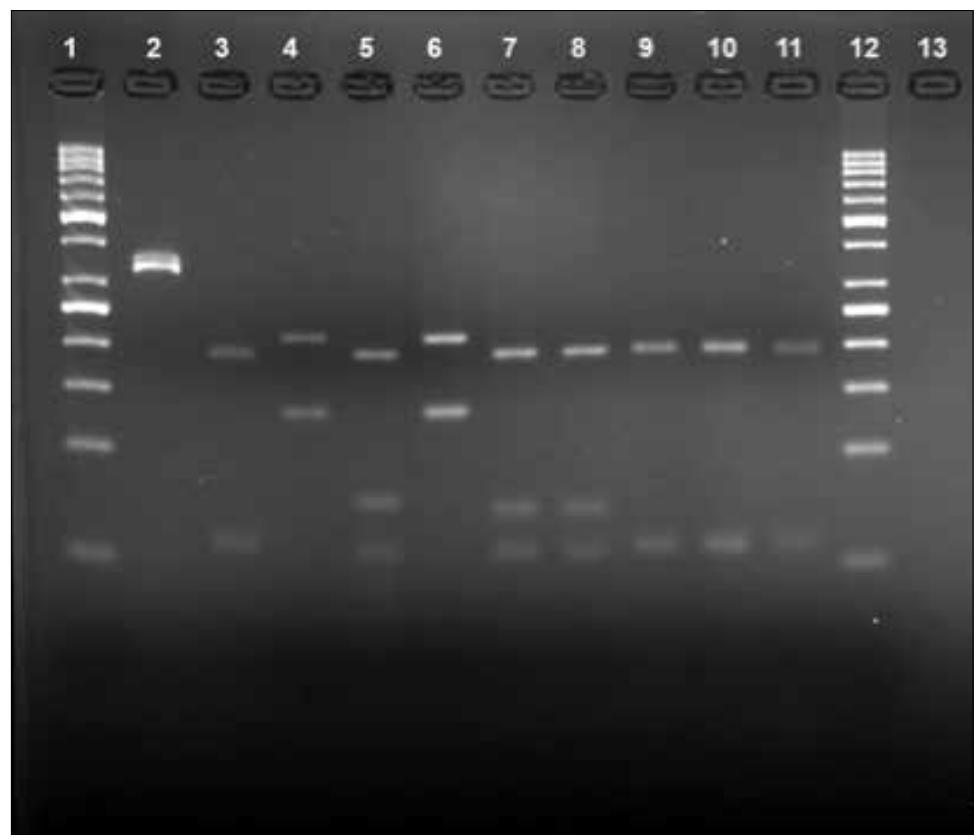

Şekil 2. ITS-1 RCR-RFLP [1: Moleküler ağırlık belirteci (50 bp), 2: Pozitif kontrol (PK), 3: RF1 (L.tropica: 200-60 bp ), 4: RF2 (L.major: 220-140 bp), 5: RF3 (L.infantum) donovani: 200-80-60 bp), 6: Pozitif hasta örnekleri (L.major), 7,8: Pozitif hasta örnekleri (L.infantum/donovani), 9,10,11: Pozitif hasta örnekleri (L.tropica), 12: Moleküler ağırlık belirteci (50 bp)].

ITS-1 gen bölgesinin LITSR ve L5.8S primerleri ile amplifiye edilen PCR ürünlerine uygulanan PCR-RFLP sonuçları değerlendirildiğinde 17 örneğin beşinin L.infantum/donovani, birinin L.major, 11'inin ise L.tropica olduğu saptanmıştır (Şekil 2).

\section{TARTIŞMA}

Ülkemizde KL, Hatay'ın da arasında yer aldığı dokuz ilde endemik olarak görülmektedir $^{7}$. Hatay'da KL olgularının çoğunun İskenderun, Altınözü, Samandağ, Yayladağı, Reyhanlı ve Antakya ilçelerinden geldiği görülmektedir. Haziran 2003-Ekim 2005 tarihleri arasında Hatay Mustafa Kemal Üniversitesi Tıp Fakültesi Parazitoloji Laboratuvarına başvuran pozitif olgular değerlendirildiğinde, hastaların çoğunun İskenderun, Kırıkhan, İskenderun/Arsuz, Serinyol, Altınözü, Samandağ, Antakya ve Harbiye'den olduğu bildirilmiştir. Yapılan çalışmalarda Hassa, Antakya, Altınözü ve Samandağ ilçelerinde bir artış olduğu bildirilmiştir ${ }^{8}$. Çalışmada pozitif olduğu saptanan örneklere ait olan bilgi formları incelendiğinde hastaların ilimizin endemik bölgelerinden geldiği ve daha çok Yayladağı, Hassa, Altınözü, Antakya (Merkez), Samandağ, Kırıkhan, Reyhanlı ve Kumlu'dan olduğu tespit edilmiştir (Şekil 3). Bu ilçelerden başvuran hastaların öyküleri dinlendiğinde, yerleşim yerlerinde benzer lezyona sahip birçok kişinin varlığından bahsedilmesi ve diğer ilçelerden başvuran hastaların bazılarının öyküsünde bu ilçelere seyahat etmiş olmaları bölgedeki olgu artışının nedenlerini açıklar niteliktedir. 


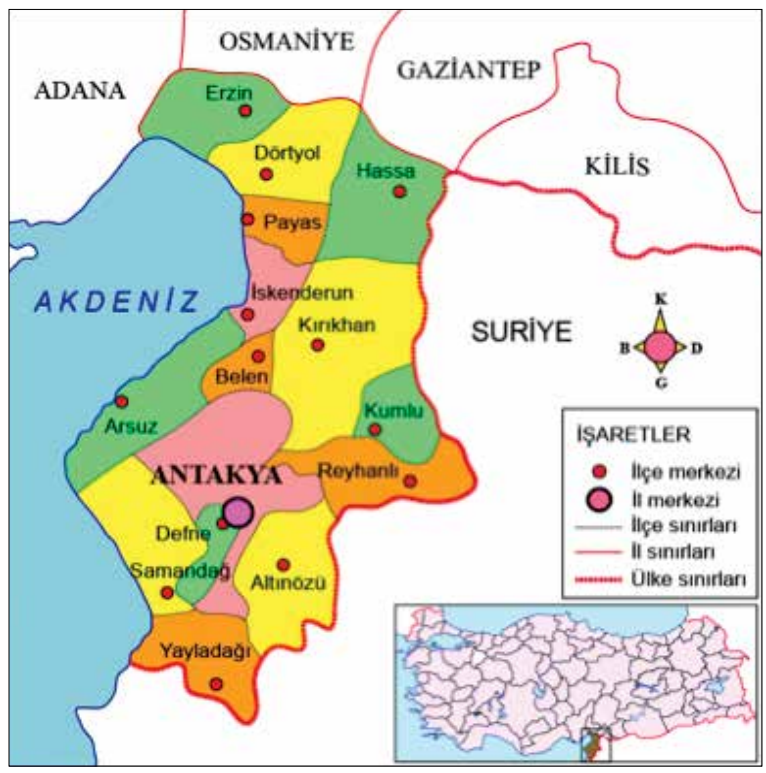

Şekil 3. Hatay ili haritasi ${ }^{27}$.

KL'nin laboratuvar tanısında altın standart yöntem; lezyonlardan hazırlanan ve Giemsa boyama yöntemi ile boyanan yayma preparatlarında parazitin mikroskobik olarak gösterilmesidir $^{7}$. Ancak, tanı için örneğin alınma şekli, parazit sayısının çok az olması nedeniyle gözden kaçabilmesi, lezyonun sekonder enfeksiyona maruz kalması, yaymaların doğru hazırlanamaması, mikroskop ile incelemede deneyimin az olması, birden fazla lezyonu olanlarda örneğin hepsinden örnek alınmaması gibi nedenler tanıyı güçleştirmektedir. Buna ek olarak, hastalığın karakterinin bilinmesi, doğru anamnez alınması ve her lezyonun KL olamayacağının da bilinmesi gerekmektedir.

Yapılan çalışmalarda, şüpheli kronik KL olgularında mikroskobik inceleme yönteminin duyarlıığının sınırlı olduğu belirtilmiştir ${ }^{17}$. Bu nedenle son yıllarda leyşmanyazisin tanısı ve tür tayini için moleküler yöntemler de kullanılmaktadır. Bu amaçla, genomik DNA (gDNA) ve kinetoplast DNA (kDNA)'daki farklı gen bölgelerinden yararlanılmaktadır ${ }^{11}$. Tüm Leishmania türlerine özgü bir gen bölgesi olan kDNA'nın içerisinde 10.000'den 20.000 'e kadar 'minicircle' bulunduğundan, tanıda kDNA-PCR yönteminin kullanılması duyarlıığı artırmaktadır. Ancak moleküler yöntemlerin maliyetinin yüksek olması nedeniyle KL'nin rutin tanısında moleküler yöntemler her laboratuvarda kullanılmamaktadır ${ }^{18}$.

Çulha ve arkadaşları 2006 yılında Çukurova'da, dermatoloji kliniğinde pozitif tanı alan 25 olguda Giemsa boyalı preparatların mikroskobik inceleme, kültür ve PCR yöntemlerini uygulayarak, bu yöntemlerin duyarlılığını karşılaştırdıkları çalışmalarında; 25 örneğin mikroskobik inceleme, kültür ve PCR yöntemlerinin sonuçlarının oranlarını sırasıyla \%44, \%68 ve \%100 olarak bulmuşlar ve KL tanısında PCR'nin en duyarlı yöntem olduğunu 
vurgulamışlardır ${ }^{18}$. Aydın'da Ertabaklar ve arkadaşları tarafından KL tanısında mikroskobik inceleme, kültür ve PCR yöntemlerinin karşılaştırılması ile ilgili yapılan çalışmada ${ }^{19}$ ise; 55 olgudan pozitif olan örnekleri dikkate aldıklarında \%78.4'ünde mikroskobik inceleme, \%92'sinde kültür ve \%81.1'inde PCR pozitifliği saptamışlar ve KL tanısında birden fazla yöntemin kullanılmasının duyarlılık ve özgüllüğü artıracağını belirtmişlerdir. Çalışmamızda 2002-2010 yılları arasında başvuran ve mikroskobik incelemesi negatif olan ancak klinik olarak KL açısından değerlendirilmesi gerektiği bildirilen kronik şüpheli KL olgularından alınan yayma örneklerinde yapılan PCR analizleri sonucunda 17 (\%34) örnek pozitif olarak tespit edilmiştir. Kronik şüpheli KL olgularında mikroskobik incelemesinde negatif olarak değerlendirilen örneklerde özellikle KL'nin endemik olduğu yerlerde moleküler tanı yöntemlerinin önemini ortaya koymaktadır.

Mouttaki ve arkadaşları tarafından 2014 yılında yapılan bir çalışmada ${ }^{20}$, kDNA gen bölgesinin $13 \mathrm{~A}$ ve $13 \mathrm{~B}$ primerlerinin $\mathrm{KL}$ tanısında oldukça hassas bir bölge olduğunu ancak Leishmania türlerini ayırt etmede yetersiz kaldığını bildirmişlerdir. Leishmania spp.'lerde bulunan ITS bölgesinin, nükleer DNA'da bulunduğu kısımdaki gen bölgelerinin, Leishmania türlerini ayırt edebilecek boyutta farklılık gösterdiği bildirilmektedir ${ }^{21}$. Başka bir çalışmada, ITS-1 gen bölgesi ile yapılan PCR ve RFLP yönteminin Türkiye'de bulunan Leishmania türlerini saptamak için iyi bir yöntem olduğu belirtilmiştir ${ }^{11}$. Hindistan'da 2007 yılında yapılan bir çalışmada ise, 32 örneğe uyguladıkları moleküler testler sonucunda kDNA-PCR'nin \%96.6 duyarlılığa, ITS1 PCR'nin \%82.8 duyarlılığa sahip olduğu bildirilmiştir ${ }^{22}$. Yapmış olduğumuz çalışmada da kDNA gen bölgesi ile pozitif/negatif olarak ayrım yapılmış ancak PCR-RFLP yöntemi için baz uzunluğu daha fazla olan ITS-1 gen bölgesi ile çalışılmasının daha uygun olduğu sonucuna varılmıştır.

Şanlıurfa'da yapılan bir çalışmada, $51 \mathrm{KL}$ şüpheli olgudan alınan örneklere PCR-RFLP yapılmış ve çalışmada PCR ile pozitiflik oranının (\%96) mikroskobik incelemeden (\%64) daha yüksek olduğu tespit edilmiştir. Elde ettikleri verilere dayanarak PCR-RFLP yönteminin, $K L$ etkenlerinin tespiti ve türlerinin belirlenmesinde duyarlı ve özgül bir yöntem olduğunu bildirmişlerdir ${ }^{23}$. Hajjaran ve arkadaşları ${ }^{24} 2011$ yılında pozitif $60 \mathrm{KL}$ hastasından izole edilen Leishmania izolatlarının türlerini 51'ini, ITS1 gen bölgesiyle PCR-RFLP analizi yaparak belirlemişler ve BsuRI (HaellI) enzimi ile yapılan PCR-RFLP yönteminin Leishmania türlerinin hızlı bir şekilde tanımlanmasında faydalı olduğunu belirtmişlerdir. Çalışmamızda ITS-1 gen bölgesi ile pozitif bulunan 17 örnek BsuRI (HaellI) enzimi ile kesilerek PCR-RFLP yöntemi kullanılarak tiplendirilmiştir.

İran'da 2013 yılında yapılan bir çalışmada, mikroskobik incelemesi negatif olan 81 $\mathrm{KL}$ şüpheli hastanın yayma örneklerinde PCR yapılmıştır. Çalışmada dokuz örnek pozitif olarak tespit edilmiş ve pozitif olan örneklerin hepsinin L.tropica olduğu bulunmuştur. Bu çalışmanın sonucunda KL tanısında yayma örneklerinin mikroskobik incelenmesinin yeterli olmadığı ve mikroskobik inceleme sonucunda negatif olduğu düşünülen fakat şüpheli deri lezyonları bulunan hastalardan alınan örneklerde çalışılan PCR yönteminin tanı duyarlılığının yüksek olduğu bildirilmiştir ${ }^{25}$. Libya'da klinik olarak şüpheli $250 \mathrm{KL}$ 
preparatı arşivden seçilerek kDNA ve ITS-1 gen bölgeleri PCR ile çoğaltılmış ve araştırmacılar kDNA ile yapılan PCR sonucunda \%22.5, ITS-1 ile yapılan PCR sonucunda \%20 pozitif sonuç elde ettiklerini belirtmişlerdir. Ayrıca araştırmacılar ITS-1 gen bölgesiyle yapılan PCR-RFLP yönteminin daha hassas, spesifik ve hızlı bir tanı yöntemi olduğunu vurgulamışardır ${ }^{26}$. Çalışmamızda mikroskobik incelemesi negatif olan 50 örneğe ait yayma preparatlarına kDNA ve ITS-1 gen bölgesi kullanarak PCR testi uygulanmıs ve özellikle kronik lezyonu bulunan şüpheli hastalarda mikroskobik inceleme ile tanı yöntemine ek olarak kDNA gen bölgesinin PCR ile çoğaltılması gerektiği sonucuna varılmışır.

2014 yılında Hatay ve Osmaniye illerinde bulunan iki KL olgusunun klinik örneklerinden yapılan kültürlerinden elde edilen Leishmania promastigotlarının gerçek zamanlıPCR ile tür tayininin yapıldığı ve ilk MALDI-TOF analizlerinin sunulduğu bir çalısmada, Hatay ilindeki KL'ye neden olan etken türün L.infantum olduğu saptanmıştır²7. Özbilgin ve arkadaşları 2011-2014 yılları arasında L.major ile enfekte olmuş 18 Türk KL hastasından aldıkları örneklerle yaptıkları bir çalışmada Hatay ilinin de yer aldığı dört coğrafik bölgeden örnek toplamışlardır. Yapılan bu çalışma ile Hatay bölgesinde KL'ye sebep olan türlerden birinin L.major olduğunu bildirmişlerdir ${ }^{2}$. Hatay'da tır şoförleri üzerinde yapılan başka bir çalışmada ise, bölgede yurt dışı kaynaklı KL'ye neden olan türler olarak L.tropica, L.infantum/donovani ve L.major bulunduğu bildirilmiştir ${ }^{13}$. Bizim yapmış olduğumuz çalışma sonucunda göç öncesi tarihlerde alınan 50 hasta örneğine ait yayma örneklerinde PCR-RFLP yöntemi ile türlerin beşinin L.infantum/donovani, birinin L.major, $11^{\prime}$ inin ise L.tropica olduğu saptanmıştır.

Sonuç olarak, özellikle endemik bölgeler için kronik lezyonu olan hastalarda KL akla getirilmelidir. Yaptığımız çalısma sonucunda, kronik KL şüphesi olan olgularda kesin mikrobiyolojik tanı için PCR yönteminin laboratuvarlarda rutin olarak kullanıımasının yanlış negatif sonuçları önleyeceği ortaya konulmuştur.

\section{Teşekkür}

Manisa Celal Bayar Üniversitesi Tıp Fakültesi Parazit Bankası'na referans suşların temin edilmesinde sağladıkları katkılardan dolayı teşekkür ederiz.

\section{ÇIKAR ÇATIŞMASI}

Yazarlar bu makale ile ilgili herhangi bir çıkar çatışması bildirmemişlerdir.

\section{KAYNAKLAR}

1. World Health Organization (2010) Control of the Leishmaniases. In: WHO Technical Report Series 949: report of a meeting of the WHO Expert Committee on the Control of Leishmaniases, Geneva, 22-26 March 2010. World Health Organization, Geneva. http://whqlibdoc.who.int/trs/WHO_TRS_949_eng.pdf

2. Karakavuk M, Aykur M, Ünver A, Döskaya M. Parasitic diseases that can infect travelers to Africa. Turk J Parasitol 2018;42(2):154-61.

3. World Health Organization. Sustaining the drive to overcome the global impact of neglected tropical diseases, second who report on neglected tropical diseases. 2013;67-71. 
4. Gürel MS, Yeşilova Y, Ölgel MK, Özbel Y. Cutaneous leishmaniasis in Turkey. Türkiye Parazitol Derg 2012;36(2):121-9.

5. Harman M. Leishmaniasis. Turk J Dermatol 2015;9:168-76.

6. Uzun S, Uslular C, Yucel A, Acar MA, Ozpoyraz M, Memişoğlu HR. Cutaneous leishmaniasis: evaluation of 3074 cases in the Cukurova region of Turkey. Br J Dermatol 1999;140:347-50.

7. Uzun S, Gürel MS, Harman M. Kutanöz layşmanyazis tanı ve tedavi rehberi. Türk Dermatoloji Derneği, Haziran 2017. Galenos Yayınevi, İstanbul, Türkiye.

8. Akçalı C, Çulha G, İnalöz S, Savaş N, Önlen Y, Savaş L, et al. Cutaneous leishmaniasis in Hatay. J Turk Acad Dermatol 2007;1(1):1-5.

9. Çulha G, Doğramacı ÇA, Gülkan B, Savaş N. Kutanöz leishmaniasis ve Hatay ilindeki durumu. Türk Hijyen ve Deneysel Biyoloji Dergisi 2014;71(4):171-8.

10. Yaman M, Özbel Y. The sandflies (Diptera: Psychodidae) in the Turkish province of Hatay: some possible vectors of the parasites causing human cutaneous leishmaniasis. Annals of Tropical Medicine \& Parasitology 2004;98(7):741-50.

11. Toz SO, Nasereddin A, Ozbel Y, Ertabaklar H, Culha G, Sevil N, et al. Leishmaniasis in Turkey: molecular characterization of Leishmania from human and canine clinical samples. Trop Med Int Health 2009;14(11):1401-6.

12. Özbilgin A, Çulha G, Uzun S, Harman M, Topal SG, Okudan F, et al. Leishmaniasis in Turkey: first clinical isolation of Leishmania major from 18 autochthonous cases of cutaneous leishmaniasis in four geographical regions. Trop Med Int Health 2016;21(6):783-91.

13. Culha G, Dogramaci AÇ, Kaya T, Çavuş I, Gülkan B, Özbilgin A. Imported cutaneous leishmaniasis cases detected in truck drivers in Hatay. Mikrobiyol Bul 2018;52(3):316-23.

14. Alan S, Başsorgun Ci. Tanıda gecikilmiş ve yüzde geniş skar bırakmış bir kutanöz leishmania olgusu. Abant Med J 2015;4(1):76-8.

15. Mohaghegh MA, Fata A, Salehi GH, Berenji F. Molecular identification of Leishmania species using samples obtained from negative stained smears. Iranian J Parasitol 2013;8(2):337.

16. Kazemi-Rad E, Mohebali M, Hajjaran H, Rezaei S, Mamishi S. Diagnosis and characterization of Leishmania species in Giemsa-stained slides by PCR-RFLP. Iranian J Publ Health 2008;37(1):54-60.

17. Rodrigues EH, Felinto de Brito ME, Mendonça MG, Werkhäuser RP, Coutinho EM, et al. Evaluation of PCR of American cutaneous leishmaniasis in an area of endemicity in northeastern Brazil. J Clin Microbiol 2002;40:3572-6.

18. Culha G, Uzun S, Ozcan K, Memisoglu HR, Chang KP. Comparison of conventional and polymerase chain reaction diagnostic techniques for leishmaniasis in the endemic region of Adana, Turkey. Int J Dermatol 2006;45(5):569-72.

19. Ertabaklar H, Çalışkan S. Ö, Boduç E, Ertuğ S. Kutanöz leyşmanyazis tanısında direkt mikroskopi, kültür ve polimeraz zincir reaksiyonu yöntemlerinin karşılaştırılması. Mikrobiyol Bul 2015;49(1):77-84.

20. Mouttaki T, Morales-Yuste M, Merino-Espinosa G, Chiheb S, Fellah H, Martin-Sanchez J, Riyad M. Molecular diagnosis of cutaneous leishmaniasis and identification of the causative Leishmania species in Morocco by using three PCR-based assays. Parasites Vectors 2014;7(1):420.

21. Ertabaklar H, Ertuğ S, Çalışkan SÖ, Bozdoğan B. Determination of Leishmania species by PCR-RFLP in the smear samples taken from the lesions of cutaneous leishmaniasis cases. Mikrobiyol Bul 2016;50(2):300-6.

22. Kumar R, Bumb RA, Ansari NA, Mehta RD, Salotra P. Cutaneous leishmaniasis caused by Leishmania tropica in Bikaner, India: parasite identification and characterization using molecular and immunologic tools. Am J Trop Med Hyg 2007;76(5):896-901.

23. Akkafa F, Dilmec F, Alpua Z. Identification of Leishmania parasites in clinical samples obtained from cutaneous leishmaniasis patients using PCR-RFLP technique in endemic region, Sanliurfa Province, in Turkey. Parasitol Research 2008;103(3):583. 
24. Hajjaran H, Vasigheh F, Mohebali M, Rezaei S, Mamishi S, Charedar S. Direct diagnosis of Leishmania species on serosity materials punctured from cutaneous leishmaniasis patients using PCR-RFLP. J Clin Lab Anal 2011;25(1):20-4.

25. Mohaghegh M, Fata A, Salehi G, Berenji F, Bazzaz MM, Rafatpanah $H$, et al. Molecular identification of Leishmania species using samples obtained from negative stained smears. Iran J Parasitol 2013;8(2):337-41.

26. El-Badry AA, El-Dwibe H, Basyoni MM, Al-Antably AS, Al-Bashier WA. Molecular prevalence and estimated risk of cutaneous leishmaniasis in Libya. J Microbiol, Immunol Infect 2017;50(6):805-10.

27. Culha G, Akyar I, Yildiz Zeyrek F, Kurt Ö, Gündüz C, Özensoy Töz S, et al. leishmaniasis in Turkey: determination of Leishmania species by matrix-assisted laser desorption ionization time-of-flight mass spectrometry (MALDI-TOF MS). ran J Parasitol 2014;9(2):239-48.

28. http://cografyaharita.com/turkiye_mulki_idare_haritalari3.html. 